\title{
Information Literacy (IL) teaching and learning: a literature review
}

\author{
George Theodore Chipeta ${ }^{4}$ \\ Department of Library and Information Science, University, Mzuzu, Malawi. \\ georgechipeta@mzuni.ac.mw
}

\begin{abstract}
The paper is largely based on review of existing literature on teaching and learning Information Literacy (IL), both online and in print. It reports on studies about the teaching and learning of IL in some institutions of higher learning. It also discusses lists of competencies, and descriptions of information literacy programmes and courses. In addition, the paper intends to compare literature on various IL undertakings in the developed countries to IL initiatives being undertaken in some developing countries, particularly, in some African Universities. The paper also discusses some challenges faced in the teaching and learning of $\mathrm{IL}$ in some institutions of higher learning. Some of these include technological issues, diverse groups, language and cultural barriers and time and lack of computers.

The paper has been able to unearth the dearth of studies on information literacy in Africa and concludes that information on IL is mostly Euro-centric; there is little happening in African countries, except for South Africa where there have a been a number of inititiatives. The paper has demonstrated that Information Literacy is being taken seriously as a module or course at some institutions of higher learning in KwaZulu-Natal, South Africa and Malawi, although a lot more needs to be done in terms of facilities and equipment which are vital in inculcating IL skills in students.
\end{abstract}

Keywords: Information literacy, teaching and learning, teaching, literature review

\section{Introduction}

This paper reviews reports and studies that focus on the teaching and learning of information literacy (IL). It also discusses lists of competencies and descriptions of IL programmes and courses. The paper intends to compare literature on various IL undertakings in the developed countries to IL initiatives being undertaken in developing countries, particularly in some African universities. Information literacy models will also be compared and discussed.

The paper discusses the following: i) The concept of information literacy; ii) Information skills; iii) Benchmarking of IL; iv) Information literacy models; v) The Seven Pillars of Information Literacy model; vi) Integration of information literacy into the curriculum; vii) Teaching and learning of information literacy; viii) Topics covered in the module or course of information literacy or library orientation programme; and ix) The challenges of the teaching and learning of information literacy.

\section{The concept of information literacy}

Shapiro and Hughes (in Malliari and Nitsos, 2008: n.p) believe that in today's society, the effective and efficient utilisation and handling of the massive volumes of print and electronic material and the various audio-visual features presupposes the existence of trained and competent users. Shapiro and Hughes (in Malliari and Nitsos, 2008: n.p) note that by definition, a competent user is one who has developed a set of skills that go beyond the basics of how to use a computer and how to access sources of information, to skills that help him/her decode the nature of information and assess its scientific, social, cultural and philosophical value.

Thus, the American Library Association (ALA, 2007: I) defines information literacy as: "A set of abilities which enable individuals to recognise when information is needed, and possessing the ability to locate, evaluate, and utilise the needed information." Living in the information era, these abilities have become imperative in virtually all life situations, and especially in the learning/educational environment.

Tertiary institutions are centres of learning and knowledge generation, meaning that students, academic staff, administrative staff, researchers and librarians work with information. Therefore, the ability to search, identify, locate, retrieve and use information independently is absolutely essential in the case of students who attend tertiary institutions to gain as much knowledge and information as possible in order to be able to function optimally in their chosen occupations.

According to the Chartered Institute of Library and Information Professionals (CILIP) (2006: n.p), IL is a part of knowledge or learning that is about acquiring a set of skills or competencies. An information literate individual cares about the quality of the answer to what he/she is investigating and is prepared to work to guarantee that quality. Barton (n.d: I2) would agree, saying that information literate students access, evaluate and use information from a variety of sources, communicate effectively, and reflect on the process as well as the product. Information Literacy is especially relevant in primary and secondary schools, institutions of higher learning, and in business and leisure (CILIP, 2006: n.p). The general

4. George Chipeta is a lecturer in the Department of Library and Information Studies at Mzuzu University, Malawi.

Inkanyiso, Jnl Hum \& Soc Sci 2010, 2(1) 
lack of access to information sources experienced on the African continent, both for educational and leisure purposes, often results in information illiterate students who are ill-prepared for the rigours of information retrieval at tertiary level. For this reason, a deliberate programme designed to teach IL should be incorporated in all universities' curricula to help students interrogate and utilise information.

This author, based on his previous experience as a student assistant in the Department of Library and Information Science and the library at the University of Zululand and current position as a lecturer in the Department of Library and Information Science at Mzuzu University in Malawi, has observed that most undergraduate students do not possess the skills they need in order to effectively conduct their research and search for information. They rely heavily on their lecture notes and on library staff in their search for information despite having been taught and equipped with IL skills during their first year at the university. One must, therefore, ask: what and where is the problem, and why are students not performing as expected with regard to the application of IL?

2.1 Information skills - what are they?

Lock (2003: n.p) states that there are two ways of approaching or categorising information skills in institutions of higher learning. The first relates to the skills that students will need to put to use during their (study) tenure, and includes the students' ability to use a library and its resources in order to advance their studies; the ability to perform literature searches to whatever depth and complexity is required for a particular curriculum or discipline area; and the ability to demonstrate this to the satisfaction of tutors and assessors by means of citations and references when using information. This approach supports the development of a competent student, one who is able to function effectively as part of the academic community.

The second category, according to Lock (2003: n.p), is about the level or degree to which students are prepared to participate in whatever activity they may choose upon leaving higher education. This requires an awareness and understanding of the way in which information is produced and some practical ideas on how information is acquired, managed, disseminated and exploited, particularly with knowledge on how professional groups use information in the workplace, in business, and in the world of culture and the arts. It also includes the critical appraisal of the content and validity of information (Lock, 2003: n.p). In order to know whether a student has mastered IL, some standards have to be made with which to measure the student. This is also known as benchmarking.

\subsection{Benchmarking information literacy in institutions of higher learning}

According to De Jager and Nassimbeni (2002:3), benchmarking is a strategic assessment tool that is commonly practised in the business sector environment and essentially consists of comparing best practices with one's own practice in order to ensure continuous improvement. The purpose of benchmarking, as noted by Meade (in De Jager and Nassimbeni, 2002:3), is to improve the current situation in order to attain excellence, and an important product of such an initiative is: "The discovery of innovative approaches $[\ldots]$ as enhancement of current practices is rarely sufficient to ensure future excellence." Information literacy has been stressed as imperative in institutions of higher learning, especially with the publication of "Information Literacy Competency Standards for Higher Education" by the Association of College and Research Libraries" (ACRL) in 1999. These are considered to be the most acceptable standards by which to measure information competencies in higher education (HE) institutions worldwide. The Council of Australian University Librarians (CAUL, 200I:4) is also an example of an organisation that provides information literacy standards as a framework for embedding information literacy in the design and teaching of educational programs and for assessing the information literate individual.

These standards are equally useful to students because they provide a framework for their interaction with information in the academic environment. They also help the students develop their awareness of the need for a metacognitive approach to learning, making them conscious of the explicit actions required when recognizing their needs and gathering, analysing and using information (CAUL, 200I:4). The Seven Pillars of Information Literacy model describes outcomes and provides examples on how to assess students' progress towards information literacy. The outcomes serve as guidelines for academics and librarians in developing local methods for measuring students' learning.

There are different ways of assessing the outcomes, and these include both higher order and lower order thinking skills. These assessment outcomes are based on Bloom's taxonomy of educational objectives, which, according to Haberle (in De Jager and Nassimbeni, 2002:3), requires students to first master the cognitive skills of the lower levels of each knowledge domain before they can master the higher levels. Azmi (n.d: 149) notes that because information literacy augments students' competencies with respect to evaluating, managing and using information, it is now considered by several regional and discipline-based accreditation associations to be a very important competency of university students. These benchmarks or standards are explained as part of information literacy models, of which several are in use today. 


\subsection{Information Literacy Models}

There are several information literacy models that have been propagated by different authors, theorists and academics. Examples of such models include:

\subsection{The Seven Pillars of Information Literacy (SCONUL, 1999)}

The Seven Pillars of Information Literacy Model was developed by the SCONUL advisory committee on information literacy in 1999. The model has seven competence levels that include the ability to recognise a need for information; the ability to distinguish the way in which the information gap may be addressed; the ability to construct strategies for locating information; the ability to locate and access information; the ability to compare and evaluate information obtained from different sources; the ability to organise, apply and communicate information to others in ways appropriate to the situation; and the ability to synthesise and build upon existing information, contributing to the creation of new knowledge (SCONUL, 1999:6).

\subsubsection{The Big6 Skills (Eisenberg and Bob Berkowitz, 1990)}

According to MacDonald and Darrow (2003:I), the Big6 Skills Model is one of the most well known models in the field and is often taught to students as a guide for their research. It is a process model that outlines how people of all ages solve an information problem. It has six stages that students follow in their information problem-solving process, namely task definition, information seeking strategies, location and access, use of information synthesis, and evaluation (Eisenberg and Berkowitz, 1990: n.p).

\subsubsection{Information Search Process (Kuhlthau, 1993)}

Another well-known model is the Information Search Process by Kuhlthau (1993). This model demonstrates how users approach the research process and how users' confidence increases at each stage. The model has seven stages, which include initiation, selection, pre-focus exploration, formulation, collection, presentation and assessment (Kuhlthau, 1993:I-3).

\subsubsection{Pathways to Knowledge (Pappas and Tepe, 2002)}

The Information Inquiry Model by Pappas and Tepe delineates pathways to knowledge and is meant to encourage students to continuously explore and reassess information as they go about their information seeking or retrieval processes. The model consists of six steps, namely appreciation and enjoyment, pre-search, search, interpretation, communication and evaluation.

The above mentioned information literacy models will be used in conjunction with other well known information seeking processes, namely Ellis's Model of Information Seeking Behaviour, Dervin's Sense Making Theory, and Belkin's Anomalous State of Knowledge (ASK) theory, in order to look at IL teaching and learning. The Seven Pillars of Information Literacy (as proposed by the Sconul committee on Information Literacy in 1999) has been selected in this paper as the focus or core model because it is closer to what students experience in reality in their daily information processes. It will therefore be used to frame the discussion, and its relevance to the other models will also be demonstrated.

\subsubsection{Research Process Model (Stripling and Pitts, 1988)}

Stripling and Pitts'Research Process Model (1988) guides students through the stages of creating a research paper. It has ten steps, starting from choosing a research topic and ending with the presentation of the final topic.

\subsubsection{The Seven Pillars of Information Literacy}

The Seven Pillars of Information Literacy Model is presented in Figure I. Other information literacy models' discussions are based on this model. Each skill is discussed and compared with some of the stages in other models. Examples of the kinds of specific activities or competences that illustrate how each skill is applied are also provided.

\subsubsection{The ability to recognise a need for information}

At this (first) stage, the user, in this case a student, is like a blank slate, with no clear knowledge of his or her information needs. Mostert (2004: 124) describes 'need' as the perception that something is lacking. It can also be seen as something that a human being requires in order to function effectively. According to Belkin (in Kituyi-Kwake 2007:82), an information need is present when a gap, uncertainty or deficiency in a person's cognitive state is recognised. Belkin (in Kituyi-Kwake 2007:82) notes that this deficiency prevents a person from making sense of the surrounding world, and to this end it is described as an "anomalous state of knowledge" (ASK), in other words a gap in one's ability to make sense of a situation. 


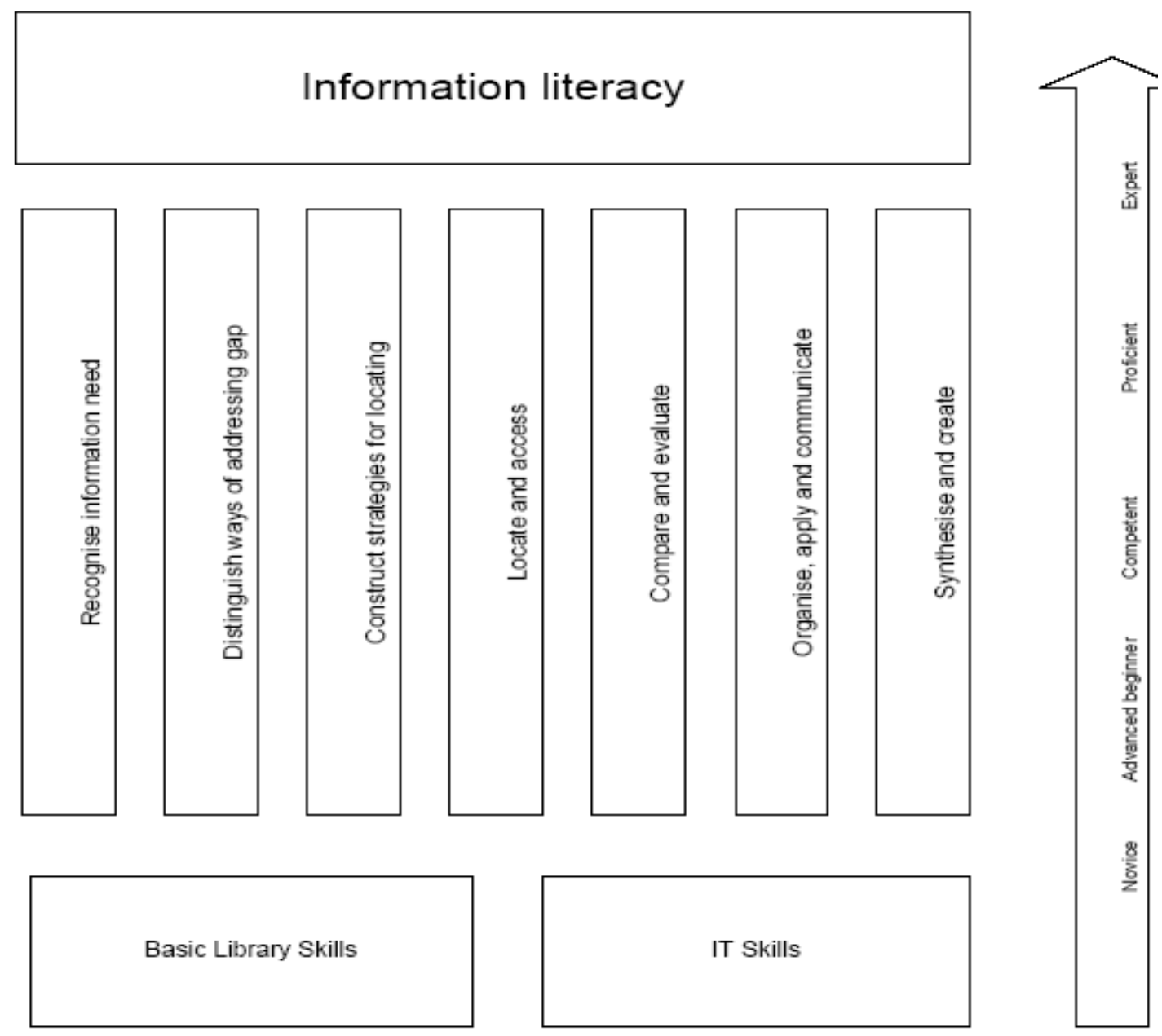

Figure 1 Information Skills model (Sourced from SCONUL position paper, 2003)

MacDonald and Darrow (2003:2) compare this stage to 'task definition' in the Big6 Skills, and 'initiation and selection' in Kuhlthau's Information Seeking Process. In task definition in the Big6 Skills Model, a student determines exactly what the problem is and determines the specific information needs related to the problem. In other words, the stage asks what information is needed in order to solve the problem at hand. This is similar to 'task initiation and selection' in Kuhlthau's Information Seeking Process Model in which an individual first becomes aware of the lack of the knowledge necessary to accomplish an assignment, which is followed by feelings of uncertainty and apprehension. At this stage, the task is to recognise a need for information. Thoughts are vague, and there is ambiguous centring on the general problem.

According to Kuhlthau (1993), a person is driven to search for information in order to address a problem as perceived by him or her. A student may therefore discuss the problem at hand with others, including peers and experts, and/or browse different sources to identify a research topic or other information need. This in turn leads the student to explore general information resources to increase their familiarity with the topic by brainstorming, discussing the problem with others, thinking about possible topics, and by tolerating uncertainty. The student then selects the topic for research. Thoughts at this stage centre on weighing topics that would best suit his or her research interests and project requirements based on the information and time available. The topic with the greatest apparent potential for success ultimately gets selected.

When selection is delayed or postponed, feelings of anxiety and confusion are likely to intensify until a choice is made. Feelings of uncertainty give way to a brief sense of elation upon selection. Actions may involve searching for information by consulting with informal mediators and making preliminary searches of the library and other sources. As already mentioned, strategies would include discussing possible topics with peers or experts and using different sources to overview possible topics. In Strippling and Pitts' Research Process Model (1988: n.p), also known as REACTS, choosing a 
broad topic and getting an overview of the topic is known as recalling, which entails fact-finding and reporting on the information.

This is followed by narrowing the topic and developing a statement of purpose, which means posing questions (e.g. whether the chosen topic will meet the users' research interests) and finding answers to such questions. It also entails exploring various forms of literature and reading, viewing and listening.

In their model, Pappas and Tepe (2002:I-2) refer to this stage as 'appreciation and enjoyment.' Appreciation and enjoyment are about 'raising' the information need. The authors argue that appreciation fosters curiosity and imagination, which in turn lead to discovery in an information seeking activity. As students go through the information seeking stages by viewing, listening, reading and sensing, their appreciation also develops and matures.

The pre-focus exploration stage in Kuhlthau's Information Search Process Model also fits in this first stage of the Seven Pillars Model. The student investigates information in order to find a focus point or she would, therefore, learn more about the general topic and identify several possible focus areas while still being unable to express the exact information that is needed. The student would therefore feel confused, doubtful, uncertain and sometimes threatened, and consequently take action by reading to gain more information and by taking notes and making bibliographic citations. Strategies that an information seeker or student would employ include summarising the notes, listing possible foci of the topic, and combining several themes to form one focus. The student then proceeds to the next stage, which is finding ways in which the information gap can be addressed.

\subsubsection{The ability to distinguish ways in which the information 'gap' may be addressed}

The second step of the information process in the Seven Pillars of Information Literacy Model entails being knowledgeable about both print and non-print information resources, selecting the information resources that would go towards accomplishing the research task, and understanding issues that affect access to information sources (Sconul, 1999:7).

Baker (2005:I-2) compares this stage to: 'focus formulation' in Kuhlthau's Information Search Process Model; 'formulating questions to guide research and plan for research production' in Pitts and Strippling's Research Process Model; and the 'pre-search stage' in the Pathways to Knowledge Model of Pappas and Tepe. Kuhlthau (I993:I-2) notes that the exploration or investigation stage in her model is the most difficult stage for users and the most misunderstood by intermediaries. Feelings of confusion, uncertainty and doubt frequently increase during this stage. The task is to investigate information relating to the general topic in order to extend one's personal understanding. Thoughts are on becoming sufficiently informed about the topic to form a focus or a personal point of view. An inability to state exactly what information is needed makes communication awkward between the user or student and the system. Actions include locating information relevant to the general topic, reading, and relating new information to what is already known. Formulation means focusing more on a specific topic within a topic. Feelings of uncertainty diminish and confidence begins to grow. The task is to develop a focus area based on the information encountered during exploration. Thoughts become clearer as a more focused and articulated concept of the topic is formed. Baker (2005:5) explains that the 'formulating questions to guide research and plan for the research production' stage of the Research Process Model, involves examining and organising (analysing) information, and asking whether the questions lay a good foundation for the research task and whether the research plan is feasible. The student then organises the information to fit the research task at hand.

In their model, Pappas and Tepe (2002:2) explain that the pre-search stage enables the users to make a connection between their topic and the knowledge that they already have in order to explore the relationships between subtopics. This requires students to brainstorm and ask what they know about their topic and what they want to know.

\subsubsection{The ability to construct strategies for locating information}

The third step in the Seven Pillars of Information Literacy Model implies articulating information needs to match the available information sources, developing a systematic method appropriate for the information needs, and understanding the principles of the construction and generation of databases. Baker (2005:1-2) compares this stage to 'information seeking strategies' in the Big6 Skills Model and 'search' in the Pathways to Knowledge Model. In order for a student to extract ideas or the right amount of information during the 'information seeking strategy', the student would need to consult a range of literature, such as journal articles, Internet sources and books on the subject. This would mean selecting a wide range of information sources and prioritising the best of all the possibilities. This is also accomplished through information seeking and requires the student to assess the value of various types of print and electronic sources, such as CD-ROMS, databases, browsing the Online Public Access Catalogue (OPAC), and so on.

The sources found would give the student an idea on how to narrow his/her broad area of interest. Ellis (in Choo, Detlor and Turnball, 2003: n.p) and Wilson (1999:6) call this 'chaining and browsing.' Chaining can either be forward or Inkanyiso, Jnl Hum \& Soc Sci 2010, 2(I) 
backward. Backward chaining occurs when pointers or references from an initial source are followed; scientists and researchers follow this routine in their information seeking processes. Forward chaining, on the other hand, identifies and follows up on other sources that refer to an initial source or document and is less commonly used. This is where the individual simplifies browsing by looking through the table of contents, lists of titles, subject headings, names of organisations or persons, abstracts and summaries, and so on. Browsing takes place when related information has been grouped together according to subject affinity, when the user views displays at an exhibition, when he or she scans a book on a shelf, etc (Ellis in Choo, Detlor and Turnball : 2003: n.p). Having accomplished this activity, the student moves on to the next activity.

\subsubsection{The ability to locate and access information.}

The fourth stage of the Seven Pillars of Information Literacy Model requires the student or information user to be able to develop an appropriate searching technique, such as the use of Boolean operators, communication and information technologies, appropriate indexing and abstracting services, citations, indexes and databases, and current awareness methods to keep up to date. To this end, the models that fit here include the Big6 Skills' 'location and access', 'information location' in Kuhlthau's Information Search Process, 'find, analyse and evaluate resources' in the Pitts and Strippling's Research Process Model and 'search' in the Pathways to Knowledge Model.

Eisenberg and Berkowitz (1990:n.p) refer to this stage as 'locating and accessing information.' This is concerned with the student selecting the most appropriate investigative methods by developing a research plan and identifying keywords, synonyms and related terms for the required information. The student thereafter constructs a search strategy using appropriate commands for the information access tool selected, such as the use of Boolean operators ("AND”, "OR" and "NOT"), truncation, and proximity operators for databases or search engines, and/or the use of OPAC, indexes and abstracts. The student goes on to retrieve information in a variety of formats using various information access tools, classification schemes and other systems, such as call number systems or indexes, to locate information resources within a library.

Kuhlthau (1993:2-3), on the other hand, refers to this as 'collection'. This is when interaction between the user and the system functions most effectively and efficiently. At this point, the task involves gathering relevant information on the focus topic. The student would have a clearer sense of direction and can specify the need for particular information. Thoughts are on searching for information to support the focus area, defining and/or extending the focus area through information, gathering pertinent information, and organising information in notes. At this point, feelings of confidence may grow considerably as uncertainty subsides and interest in the project intensifies. Actions focus on using the library and other resources to collect significant information, and taking detailed notes with bibliographic references. Strategies that are used include using keywords to search for significant information; comprehensively searching various types of materials, such as references, periodicals and non-fiction; using indexes; and requesting assistance from the librarian. This stage is equivalent to 'find, analyse and evaluate resources' in the Research Process Model in which students ask themselves whether the sources found are usable and adequate.

In the search stage of the Pathways to Knowledge Model, Pappas and Tepe (2002:3) explain that users identify appropriate information providers such as libraries, records and archive centres, museums and so on; select information resources and tools such as indexes, people, the Internet, the media and references resources; and then plan and implement a search strategy to find information relevant to their research question or information need. This they can accomplish by scanning, interviewing and confirming information sources and recording information to determine the relevance of the information, and by exploring and browsing widely. Ellis (in Choo, Detlor and Turnball: 2003: n.p) refers to this as 'extracting', which is an activity of systematically working through a particular source or sources in order to identify materials of interest. This is achieved by directly consulting the source(s) or by indirectly looking through bibliographies, indexes or online databases.

\subsubsection{The ability to compare and evaluate information obtained from different sources}

The fifth stage of the Seven Pillars of Information Literacy Model signifies that students should be aware of bias and authority issues, in other words the peer review process of scholarly publishing and appropriate extraction of information matching the information need. This is compared to 'evaluation' in the Big6 Skills Model, 'search closure' in Kuhlthau's Information Search Process, 'evaluating evidence/taking notes and compiling a bibliography' in the Research Process Model, and 'interpretation' in the Pathways to Knowledge Model.

Eisenberg and Berkowitz (1990: n.p) explain that the student assesses the quantity, quality and relevance of the search results to determine whether alternative information access tools or investigative methods should be utilised, identifies the gaps in the information retrieved, and determines if the search strategy should be revised. The student repeats the search using the revised strategy when necessary, summarises the main ideas extracted from the information gathered, 
and examines and compares information from various sources to evaluate the information's reliability, validity, accuracy, authority, timeliness and point of view. The student should be able to recognise the cultural, physical, or other contexts within which the information was created and should understand the impact of context when interpreting information. In 'search closure', Kuhlthau (1993:3) asserts that the task is to wrap up the search for information. A student's thoughts are immersed in identifying whether this would increase redundancy and exhaust all resources.

At this stage, the student could feel a sense of relief, satisfaction, or disappointment. The student rechecks sources for information that might have gone unnoticed from the outset and confirms information and bibliographic citations relevant to the focus area and research questions. Strategies would include returning to the library to sum up the search and keeping the necessary books while writing to recheck information. Baker (2005:5) explains that 'evaluating evidence or taking notes and compiling a bibliography' in the Research Process Model involves judging information on the basis of authority, significance, bias and other factors.

Ellis's model of information seeking behaviour refers to this as 'differentiating' (Ellis in Choo, Detlor and Turnball: 2003: n.p). This means that the student filters and selects from among the sources scanned by noticing differences between the nature and quality of the information offered. Priority of sources and types of sources can be made according to three main criteria, namely substantive topic, approach or perspective, and level, quality, or type of treatment. The differentiating process is likely to depend on the individual's prior experiences with the sources, word of mouth recommendations from personal contacts, or reviews in published sources.

\subsubsection{The ability to organise, apply and communicate information to others in ways appropriate to the situation}

This stage calls for students or researchers to cite bibliographic references in their academic works, construct a personal bibliographic system, apply information to the problem at hand, communicate information effectively using the appropriate medium, and to understand issues pertaining to copyright and plagiarism (SCONUL, 1999:6). This is similar to 'information use' in the Big6 Skills Model and 'communication' in the Pathways to Knowledge Model. According to Pappas and Tepe (2002:3), the communication stage allows students to organise, apply, and present new knowledge that is applicable to their research questions or information needs. In applying information, students choose an appropriate communication format and respect intellectual property. In sharing knowledge, they compose, design, edit, revise and use the most effective medium (e.g. video, report, animation, etc.) and convey the information.

In communicating information to others, the student should understand cultural, ethical, legal, and socio-economic issues surrounding information and identify and articulate issues that relate to privacy. In addition, the student needs to note security in both the print and electronic environments, identify and articulate issues in relation to free versus feebased access to information, identify and discuss issues in relation to censorship and freedom of speech, and demonstrate an understanding of intellectual property, copyright and the fair use of copyrighted materials. To avoid issues of plagiarism, the student should acknowledge the use of information sources by selecting an appropriate citation style in project reports and theses.

\subsubsection{The ability to synthesise and build upon existing information, contributing to the creation of new knowledge}

'Synthesis' in the Big6 Skills Model by Eisenberg and Berkowitz, 'presentation' in Information Search Process by Kuhlthau, and 'establish conclusions or organise information in outline and create and present final product' in the Research Process Model by Pitts and Stripling compare favourably to the seventh stage of Seven Pillars Model.

According to Eisenberg and Berkowitz (1990: n.p), synthesising information means that the student brings information together and relates what he or she has learned to what he/she already knows. The student chooses a communication medium and format that best supports the purposes of the product and the intended audience. This entails writing a draft that links various segments of information into a coherent whole and revising the draft a number of times to improve understanding before submitting it. In Kuhlthau's (1993: n.p) model, this stage falls under presentation. The task is to complete the search and to accomplish the assignment. A sense of relief is common, with satisfaction if the search has gone well and disappointment if it has not. Thoughts centre on culminating the search with a personalised understanding of selected aspects of the topic under study. Finally, the student has to combine concepts into potentially useful primary statements with supporting evidence and integrate the prior and new information, including words and ideas, in a manner that supports the purposes of the project.

In establishing conclusions and organising information in an outline, Pitts and Stripling (Stripling and Pitts, 1988: n.p) explain that the student or researcher draws conclusions by developing a personal perspective based on the obtained information. The outline should logically arrange conclusions and evidence. In creating and presenting the final product, Pitts and Stripling (Stripling and Pitts, 1988: n.p) are of the view that this should reflect on whether the paper is satisfactory.

Inkanyiso, Jnl Hum \& Soc Sci 2010, 2(I) 
The above competencies can be inculcated in students by teaching them in formal classes in their respective subjects. If the module or course of information literacy is to be taught in formal classes and marked, it has to be embedded into the curriculum of the teaching department.

\section{The teaching of Information Literacy in Institutions of higher learning with special reference to South African universities: case studies.}

Schaffner, Stebbins, and Wyman (in Allen, 2000: n.p) suggest that in order to improve active undergraduate education, resource-based learning should be the standard model of learning on university campuses. It also incorporates undergraduate research, service learning, inquiry learning, problem-based learning, and evidence-based learning. Additionally, it fosters the achievement of information literacy competencies and results in tangible outcomes or accomplishments, e.g. in the case of a solution to a community problem. Dazkiw and Forsyth (2003:3) present an example of resource-based learning at La Trobe University in Canada, where information literacy as a subject for the Bachelor of Nursing degree was published and presented online in WebCT modules and delivered as a set of lectures. Formal lectures were improved with standard tutorials, and workshops.

There are several information literacy initiatives in South Africa. One such initiative, the most prominent in fact, is the Information Literacy (INFOLIT) project, established in 1995. According to Underwood (2002:5), the primary objectives of INFOLIT (as of 1995) are to promote the concept, value and importance of information literacy, and to launch a series of pilot projects, explore and establish means of spreading information literacy education in the Western Cape region. The tangible outcomes of the INFOLIT project have been the recognition of the importance of IL at the University of Stellenbosch, University of Cape Town, Peninsula Technikon, Cape Technikon and the University of the Western Cape. The INFOLIT project also culminated in sponsoring the development of a web-based IL course. The site is meant to help users find, evaluate, use and communicate information. It is available at all the tertiary institutions in the Western Cape Province (Underwood, 2002:7). Underwood (2002:8) reports that the INFOLIT project also led to the establishment of a Centre for Information Literacy at the University of Cape Town. The members of staff at the centre are responsible for working with the academic staff of all the university's faculties in order to develop strategies for the integration of IL within the faculties' curricula. A series of discipline-based workshops on web-searching were developed using a template. The workshops were delivered on request to academic and library staff and students at each of the five institutions in the Cape region (Underwood, 2002:8).

According to De Jager, Nassimbeni and Underwood (2007:143), most institutions of higher learning offer library orientation or training that includes the use of the OPAC, electronic databases, citations and referencing. These authors also note that there is growing evidence of a greater number of IL modules being embedded in various curricula. While most of the courses are still generic stand-alone courses, others are credit bearing. Most institutions have a librarian whose primary responsibility is IL education, very often supported by subject librarians who offer training in their specific fields or disciplines. Some of the training is delivered in classrooms or computer laboratories, while other forms of training are offered virtually through platforms such as Web-CT. A training librarian made the point, however, that at her institution they were unable to offer an online course because many of their students come "from rural areas, farms and townships where there are no libraries and computers" (De Jager, Nassimbeni and Underwood (2007: 143).

The former Rand Afrikaans University launched a multimodal approach to teaching and learning in 2003. The multimodal approach was aimed at optimisation, learning and assessment, and has been defined as the use of different media or modes of delivery of teaching. The different media and technologies used in this integrated, multimodal learning environment include lectures, support from tutors, paper-based learning guides, interactive CDs, textbooks, videos, video-conferencing, and the web (electronic classes based on WebCT software offered to students via the Edulink virtual learning environment portal) [Molepo and van Vuuren, 2005: I44].

According to Kibirige (2005:I3I), the learning and teaching processes at Monash University, South Africa, involve, in some instances, customised classes for groups of students for search assistance related to a specific assignment. Such a session covers the Voyager catalogues as well as reference works, search strategies and online databases relevant to an essay topic. Through liaisons between the library and the Center for Learning and Teaching, some lecturers attend information literacy workshops taught to subject groups on an ad hoc basis. Other initiatives include curriculum integrated sessions, where there is one formally scheduled session on the academic timetable - a two-hour class on 'Doing research on the Internet' as part of a first year course in contemporary studies. Students complete an assignment for credit towards their semester mark, and develop the skills that are necessary for effective Internet research by completing specific exercises. This model could be extended to other course units (Kibirige, 2005:I3I).

Chipeta, Mostert and Jacobs (2008:52), in their study on "Teaching and learning of Information Literacy in some selected institutions of higher learning in KwaZulu-Natal province, South Africa and Malawi”, established that IL is offered and taught 
as a module or course by the Departments of Library and Information Science at the University of Zululand (Unizul) and Mzuzu University (Mzuni), where it is embedded in the departments' curricula. While it is not formally offered by the Durban University of Technology (DUT), it forms part of the library orientation programme. Both Unizul and Mzuni also offer it as part of the library orientation programme, but it is not compulsory to attend.

Chipeta, Mostert and Jacobs (ibid) further found that the methods of designing the formal courses differ in the two institutions that offer it. Whereas the best practice for the design and review of the curriculum is through the involvement of various stakeholders, such as librarians, administrators, lecturers and curriculum designers, this is not always the case. In the case of Mzuni, the LIS Department hosts a workshop where participants, mainly lecturers from the LIS Department and librarians from across and outside the country, deliberate on and design a curriculum that is acceptable to all parties. This is reviewed on an annual basis. At Unizul, however, the course is designed and reviewed periodically by the lecturer concerned in consultation with the Head of the LIS Department. In terms of how the formal courses are offered, the study established that it was mostly by way of lectures in class, group discussions, and hands-on use in the library (browsing and using the Open Access Public Catalogue and other library resources). The informal library orientation programmes took the form of a theoretical introduction to the library, a walkabout in the library to familiarise students with the whereabouts of the information sources, and a one hour practical hands-on introduction to the OPAC. Attendance of the orientation programmes is not compulsory and skills learned are not tested or credited to the student. This method corresponds with one at the Chinese University of Hong Kong, Hong Kong, China where according to Li, Leung and Tam (2007: 534), the reference librarians at the University Library System (ULS) conduct the user education or information literacy instruction through the face to face classroom instruction.

Chipeta, Mostert and Jacobs (2008: 117) in their study, ascertained that common topics in the two institutions include sources of information, searching and retrieval tools, the use of I-Link OPAC, the use of the Internet and electronic sources such as databases, evaluating and manipulating information in a usable form, arrangement of information resources in the library, communicating information, and citing and referencing academic works. Modes of delivery mainly consisted of lectures, group discussions and practicals in the computer laboratory, and both theory and practical modes in the library.

Several problems in the teaching and learning of information literacy are pinpointed here and were discussed in Chipeta, Mostert and Jacobs' (2009) paper. These include technological issues, diverse groups, language and cultural barriers, and lack of time and resources such as computers.

Insufficient computer resources and slow Internet connections make the efficient teaching of information literacy very difficult. The problem of slow connectivity affects the time frame in which a topic could be taught and its completion (Dazkiw and Forsyth (2003:7). To compound the problem, some students do not have any computing skills.

This view concurs with Chipeta, Mostert and Jacobs (2009:53) that some topics, such as the use of the OPAC, databases, and search engines, require the use of computers and the Internet. Therefore students need to be computer literate. The study established that the inability to operate computers sufficiently slowed down teaching during practical sessions and was particularly frustrating to the library staff since they only had one hour to teach students all that they needed to know about the library and how to search for information. This often resulted in sessions being virtually fruitless as tasks could not be completed or practised. Erratic network connections due to viruses and power disruptions at both the University of Zululand and Mzuzu University were other common problems. Chipeta, Mostert and Jacobs (2008:125) in their study viewed 2008's load shedding as a crisis in South Africa that was beyond the affected universities' control; it is also a national and regional crisis that generally afflicts most of the countries in the Southern African region. Power blackouts tend to disrupt the teaching and learning of IL because classes are based on the use of electronic equipment, e.g. computers, overhead projectors and the Internet. Once power goes out, the computers' network server is disrupted and classes have to be dismissed.

Another problem, as highlighted by Winfred and Manning (in Selematsela, 2005:30), is that the student population in South Africa is very diverse and teachers are responsible for classrooms that represent students of different racial and ethnic groups, religions, languages, backgrounds, ages and learning styles and computer skills. As such, students enter the university with extreme polarity in their skills levels, thereby making it difficult for academic and library staff to pitch information literacy sessions at the same level (Moore and Abson in Selematsela, 2005:30). Winfield and Manning (in Selematsela, 2005:30) note that diversity in the case of students can be classified according to intergroup or individual differences. Intergroup differences are more pronounced in socio-economic levels; racial, ethnic and language groups; and physical ability. Within the inter-group differences and within each learner group, there are individual differences in learning rates, attitudes and motivational rates, which have a bearing on the achievement outcomes that academic and library staff must accommodate.

Inkanyiso, Jnl Hum \& Soc Sci 2010, 2(1) 
Yet another problem identified by Selematsela (2005:3I) is that most learners that study in South African universities come from Southern African Developing Countries (SADC) and beyond and also include local learners whose mother tongue is not English. Most of these learners use English as a second language. This has some implications on their learning. Conteh (in Selematsela, 2005:31) asserts that the inclusion of learners from diverse language and cultural backgrounds in the same information literacy instruction session becomes problematic in the teaching of information literacy and increases the risk of misunderstanding. Students from disadvantaged backgrounds have unique obstacles that they have to overcome in order to be able to independently use library and information resources. Issues such as communication, learning styles and students' previous experiences should be taken into account by the lecturers and instructors. In addition to language barriers, there are also cultural barriers, which include students' reluctance to ask for help and their shyness and respect of authority.

Chipeta, Mostert and Jacobs (2009:53), in their study at UniZul and the DUT in KwaZulu-Natal in South Africa and Mzuni in Malawi, found that time plays a very important role in the teaching of IL. The shorter the time selected for teaching, the more likely it is that the teaching would be ineffective. If, on the other hand, the teaching period is longer, there is a higher likelihood that students would grasp the topics under discussion. All the staff members interviewed cited lack of time as a common problem. For the library orientation programmes, only one-hour slots per student group were allocated, and even departmental staff that had a whole term to teach IL cited these time slots as inadequate, especially in terms of practical work.

The teaching of IL also requires a setting where there are computers for students' practicals. This contributes to a smooth teaching and learning environment. A shortage of equipment and/or venues means limited access to computers, and therefore fewer practicals. Chipeta, Mostert and Jacobs (2009: 53) found this to be a perennial problem at Unizul, DUT and Mzuni, especially in their libraries which require the equipment onsite for practical orientation. The staff teaching the course experienced the same problem, having to make use of computer laboratories that were mostly double-booked with other courses (Unizul) or always used by computer science students, not leaving much room for any other classes (Mzuni). The author observed that students often simply did not pitch up for classes because they knew about these problems.

\subsection{Conclusion}

The study has been able to unearth the dearth of studies on information literacy in Africa. This is supported by the fact information on IL is mostly Euro-centric, there is little happening in African countries, except for South Africa in which there have been a number of inititiatives.

The paper has demonstrated that Information Literacy is being taken seriously as a module or course at some institutions of higher learning in KwaZulu-Natal, South Africa and Malawi, although a lot more needs to be done in terms of facilities and equipment which are vital in inculcating IL skills in students. If IL instructors are to teach effectively, they have to be given the necessary support in terms of tools, otherwise they may end up with students who do not know how to independently search, identify, locate and use information. All in all, institutions of higher learning should incorporate IL courses in their curricula and it should be made mandatory to teach students such a course.

\section{References}

Allen, L. 2000. Information Literacy in Higher Education: A Revolution in Learning. (Online): Retrieved May 7, 2007 from http:// www.pages.drexel.edu/ la35/Information_Literacy_in_HigherEducation.html.

Association of Research and College Libraries. 2000. Information Literacy competency Standards for Higher Education (Online): Retrieved on March 20, 2007 from http://www.ala.org/ala/acrl/acrlstandards/informationliteracycompetency.htm

American Library Association. 2007. Information Literacy competency Standards for Higher Education (Online): Retrieved on March 20, 2007 from http://www.ala.org/ala/acrlbucket/homepagecontent/contactacrl.htm .

Azmi, H. n.d. Teaching Information literacy Skills. A case study of the QU core programme in Qatar University. (Online): Retrieved on Aprill 5, 2008 from http://www.ics.heacademy.ac.uk/italics/vol5iss4/azmi.pdf

Baker, K. 2005. Baker model. (Online): Retrieved on February 20, 2008 from http:www//virtualinquiry.com/inquiry/ bakermodel.pdf.

Barton, H. n.d. Information Literacy: Learning How to Learn. (Online): Retrieved March 5, 2007, from http://www.ri.net/ RITTI_Fellows/Barton/infolit.html.

Chatered Institute of Library and Information Professionals. 2006. A short introduction to information literacy. (Online): Retrieved March 4, 2007 from http://www.cilip.org.uk/professionalguidanceinformationliteracy/definition/introduction. htm.

Chipeta, G. Mostert, J. and Jacobs, D. 2009. Teaching and learning of information literacy in some selected institutions of higher learning in KwaZulu-Natal and Malawi. South African Journal of Libraries and Information Science (SAJLIS), Vol 74 (2); 53.

Chipeta, G. 2008. Teaching and learning of information literacy in some selected institutions of higher learning in KwaZulu-Natal and Malawi. Masters Thesis, unpublished. KwaDlangezwa: University of Zululand.

Choo, C.W., Detlor, B., and Turnball, D. 2000. Information Seeking on the Web: An Integrated Model of Browsing and Searching. (Online): Retrieved on July 5, 2007 from http://www.firstmonday.org/issues5_2/choo/index.htm. 
Council of Australian University Librarians. 200I. Information Literacy Standards. Retrieved March I5, 2007 from http:// www.caul.edu.au/caul-doc/InfoLitStandards200I.doc.

Daskiw, J. and Forsyth, B. 2004. And the winners are Students, Academic staff and Librarians: A case study at La Trobe University. (Online): Retrieved April 17, 2008 from http://lifelonglearning.cqu.edu.au/2004/papers/dazkiw-28-paper.pdf

De Jager, K. and Nassimbeni, M. 2002. Can they do and do they? Exploring the Information Literacy in South African tertiary institutions. A Paper presented at LIASA (2002): Port Elizabeth, South Africa. (Online): Retrieved March I0, 2007 from http:/ /home.imaginet.co.za/liasa/Karin\%20\&\%20Mary2002.rtf.

De Jager, k., Nassimbeni, M., and Underwood, P. 2007. Libraries, Literacies and learning: retrospect and prospects.[Online]: retrieved on 25 March 2007 from http://www.dissanet.com/ifla/pdf/LIASA\%252010\%2520De\%2520Jager,\% 2520 Nassimbeni\%2520\%26\%2520Underwood.pdf+De +jager, + nassimbeni + and + Underwood\&hl=en\&ct $=c l n k \& c d=3 \& g l=$ za\&client $=$ firefox- $a$

Eisenberg, M. and Berkowitz, B. 1990. A Big6 Skills overview. (Online): Retrieved 2007 from http://www.big6.com/ showarticle.php?id= 16 .

Kibirige, S.N. 2005. The current status of information literacy training at Monash South Africa in Kiondo, E and Msuya (eds), J, User Information Literacy: case studies from University Library programmes in the SCANUL-ECS region. Bristol: INASP.

Kituyi-Kwake, A.W. 2007. The role of Information and Communication Technologies in Harnessing Information for women in rural development: Case studies of South Africa and Kenya. Ph.D Thesis. University of Zululand.

Kuhlthau, C.C. 1993. Information Search Process. (Online): Retrieved on June 10, 2007 from http://www.Scils.rutgers.edu/ $\sim$ Kuhlthau/Information_Search_Process.htm.

Li, L. F., Leung, S., Tam, G. 2007. Promoting information literacy skills through web-based instruction: The Chinese university of Hong Kong experience. (Online): Retrieved January 10,20I 0 from www.emeraldinsight.com/0 I 43-5 I 24.htm.

Lock, S. 2003. Information Skills in Higher Education: A SCONUL Position Paper. (Online): Retrieved May 7, 2007 from http:// www.sconul.ac.uk/groups/informationliteracy/papers/Sevenpillars.html.

MacDonald, C. and Darrow, R. 2003. Information Literacy models and comparison Chart. (Online): Retrieved on May I5, 2007 from http://www.infopeople.org/training/past/2004/k-infolit/ handout infolimodels/.pdf.

Molepo, C. and Vuren, A. V. 2005. User education at the Rand Afrikaans University in Kiondo, E and Msuya (eds). User Information Literacy: case studies from University Library programmes in the SCANUL-ECS region J.Bristol: INASP.

Mostert, B.J. 2004. Parliamentary Information Sources, Systems and Services in South Africa and the role of parliamentary Libraries and Information provision. Ph.D Thesis. KwaDlangezwa: University of Zululand.

Pappas, M.L. and Tepe, A.E. 2002. Pathways to Knowledge and Inquiry Learning. (Online): Retrieved on March 20, 2007 from http://virtualinquiry.com/inquiry/pathways.htm.

Selematsela, D.N.S. 2005. Strategies in Information Literacy Instruction in academic Information Services. Ph.D.Thesis Unpublished. Johannesburg: University of Johannesburg.

Society of College, National and University Libraries. 1999. Information Skills in Higher Education: A Sconul Position paper. (Online): Retrieved May 7, 2007 from http://www.sconul.ac.uk/groups/informationliteracy/papers/Sevenpillars.html

Stripling, B. and Pitts, J. 1988. Brainstorm and Bluesprints: Teaching Research as a Thinking Process. (Online): Retrieved from http://Virtualinquiry.com/inquiry/strpling.htm

Underwood, P. 2002. A case study in Development through Information literacy. A white paper prepared for UNESCO, the U.S. National Commission on Libraries and Information Science, and the National Forum on Information Literacy, for use at the Information Literacy meeting for experts, Prague, the Czech Republic. (Online): Retrieved March 25, 2008 from http// www.nclis.gov/libinter/infolitconf\&meet/papers/underwood-fullpaper.pdf.

Wilson, T.D. 1999. Models in Information Behaviour Research. (Online): Retrieved on October 5, 2007 from Journal of Documentation, 55 (3). http://informationr.net/tdw/publ/papers//999JDoc.html 